STUDI

FRANCESI

\section{Studi Francesi}

Rivista quadrimestrale fondata da Franco Simone

165 (LV | III) | 2011

LA RAPPRESENTAZIONE DELLA MADRE NELLA

LETTERATURA FRANCESE DEL NOVECENTO a cura di Dario Cecchetti e Michele Mastroianni

\title{
Héroissme et Lumières, Études réunies par Sylvain Menant et Robert Morrissey
}

\section{Olga Penke}

\section{OpenEdition}

Journals

\section{Édition électronique}

URL : http://journals.openedition.org/studifrancesi/5013

DOI : 10.4000/studifrancesi.5013

ISSN : 2421-5856

\section{Éditeur}

Rosenberg \& Sellier

Édition imprimée

Date de publication : 1 décembre 2011

Pagination : 641

ISSN : 0039-2944

Référence électronique

Olga Penke, "Héroïsme et Lumières, Études réunies par Sylvain Menant et Robert Morrissey ", Studi Francesi [En ligne], 165 (LV | III) | 2011, mis en ligne le 30 novembre 2015, consulté le 09 janvier 2021. URL : http://journals.openedition.org/studifrancesi/5013; DOI : https://doi.org/10.4000/studifrancesi. 5013

Ce document a été généré automatiquement le 9 janvier 2021.

\section{(†) $\odot$

Studi Francesi è distribuita con Licenza Creative Commons Attribuzione - Non commerciale - Non opere derivate 4.0 Internazionale. 


\title{
Héroïsme et Lumières, Études réunies par Sylvain Menant et Robert Morrissey
}

\author{
Olga Penke
}

\section{RÉFÉRENCE}

Héroïsme et Lumières. Études réunies par Sylvain MENANT et Robert MORRISSEY avec la collaboration de Julie MEYERS, Paris, Honoré Champion, 2010 (Collection «Moralia» n. 16, dirigée par Jean Dagen), pp. 284.

1 Le sujet de ce recueil d'études passionnant s'inscrit dans une perspective théorique bien définie dans l'introduction de Robert MORRISSEY et la conclusion de Jean-Claude BONNET (pp. 7-15 et 251-255). Les contributions traitent de l'art militaire, de l'héroïsme guerrier et de la culture des officiers de l'armée. L'accent y est mis sur la représentation des transformations des anciennes valeurs philosophiques, morales, politiques et esthétiques et d'une mentalité nouvelle qui donnent à la notion une signification très particulière dans un siècle que l'on peut qualifier de pacifique. La complexité de ces changements est présentée au cours d'un long XVIII ${ }^{\mathrm{e}}$ siècle (1685-1815), au bout duquel l'héroïsme n'est plus respecté comme valeur morale représentant l'autorité et les qualités militaires, mais se transpose dans des talents plus "modérés" et pacifiques et trouve de nouveaux terrains dans l'esthétique du théâtre, de la peinture, dans la musique et l'opéra.

2 Le livre est organisé autour de trois centres d'intérêt. La première partie, intitulée «Héritage et traditions» est composée de cinq études. Daniel RocHe donne un cadre pour le volume entier en exposant le transfert de la valeur de l'héroïsme depuis l'Antiquité jusqu'à la fin du xvIII ${ }^{\mathrm{e}}$ siècle dans les modèles du comportement et de la mentalité représentés par les moralistes et les artistes, de la survie d'un héroïsme qui se teinte pourtant d'une vision éthique, faisant appel à la générosité et à la vertu, vers 
l'apparence, se référant à l'esprit cavalier, vidé de sens (L'héroïsme cavalier: fin XVI siècledébut XVIII ${ }^{e}$ siècle, pp. 19-36). La représentation en armure, sous-genre codifié depuis la Renaissance, met en valeur l'autorité. Philippe BORDEs démontre comment les valeurs guerrières perdent leur importance dans l'iconographie picturale et comment les signes traditionnels de l'héroïsme laissent place à la souplesse et à la légèreté que les artistes introduisent vers les années 1760 (Le portrait en armure à l'épreuve des Lumières, pp.37-51). Sylvain MENANT met en contraste la production littéraire fictionnelle, qui utilise l'ironie pour représenter l'héroïsme, avec les histoires qui exaltent ses versions philosophiques et remplacent le héros par le grand homme, utile pour le bonheur de la société. Il complète cette image par l'analyse de l'Encyclopédie qui attache un grand soin à l'art militaire moderne, c'est-à-dire à celui qui diminue l'exploit individuel et met l'accent sur la rationalisation (L'héroisme en uniforme dans la littérature des Lumières, pp. 87-102). Deux études se concentrent plus particulièrement sur l'esthétique. Larry NoRMAN met en rapport l'héroïsme de type nouveau avec les notions du «sublime» et «de la grandeur poétique» dans la querelle des Anciens et des Modernes (La philosophie à l'assaut de l'héroïsme dans "La Querelle d'Homère", pp. 53-64). Downing тномAs prend l'exemple des tragédies mises en musique, pour montrer que les artistes cherchent à intensifier l'effet de la tragédie par la musique, voulant éveiller des sentiments puissants (Lyric Heroes, pp. 65-85).

3 La deuxième partie permet d'élargir le sujet au sens particulier des «Figures historiques». Le XVIII ${ }^{\text {e }}$ siècle est «un temps où l'on est beaucoup revenu de l'admiration du héroïsme», comme le remarque Montesquieu, qui utilise encore cette forme, tandis que Voltaire écrira «l'héroïsme». L'image d'Alexandre, présentée par Pierre BRIANT illustre bien cette pensée: ce personnage apparaît dans les textes philosophiques et politiques soit comme grand homme, soit comme antihéros (Alexandre: "héros" des Lumières, pp. 105-115). La représentation de Bélisaire subit un changement de même type. Anne-Sophie BARROVECCHIO démontre comment de militaire il devient homme malheureux, et même philosophe, partisan de la tolérance dans le roman "moral" de Marmontel (Un héros philosophe, Bélisaire? pp. 117-132). En même temps, l'héroïsme est refusé à certains personnages des épopées antiques, auxquels la signification moderne de l'honnêteté semble manquer. La figure de Jeanne d'Arc, femme guerrière, subira un changement quelque peu différent dans La Pucelle de Voltaire où elle est honnête, mais trop simple, aussi son entourage perd toute grandeur: les rôles sociaux et sexuels sont inversés, le roi devient ridicule, l'ensemble des Français se caractérise par sa mollesse, des Anglais par leur force physique et morale (Jennifer TSIEN, Jeanne ou l'oubli du héros pp.133-152). Johnson K. WRIGHT rapproche deux représentations de Phocion, celle picturale de Poussin et celle littéraire de Mably et montre comment la représentation de cette figure se transforme du milieu du XvII ${ }^{e}$ jusqu'à la fin du xvIII ${ }^{e}$ siècle: il personnifie d'abord la conception stoïcienne de l'existence, puis l'union de la politique et de la vertu. Ce héros sera évoqué pendant la Révolution française quand il semble imposer le choix nécessaire entre le modèle spartiat et athénien de la démocratie (Phocion in France: Adventures of a Neo-Classical Hero, pp. 153-176).

4 Le livre, qui suit l'ordre chronologique, se conclut par «Le Tournant Révolutionnaire», l'époque la plus variée du point de vue du sens de la notion. Philippe ROGER présente dans Avatars de l'héroïsme au siècle des Lumières la chute de l'héroïsme et sa redéfinition qui aboutit pendant la Révolution à la "restauration" du héros qui se sacrifie pour la collectivité et cela dans des genres aussi divers que l'opéra, l'histoire, la prose 
philosophique, l'épopée ou le chant (pp.179-201). La réhabilitation de la violence est voilée par le thème de la fraternité dans le théâtre de la Révolution qui réintroduit l'héroïsme militaire et redécouvre les héros de l'Antiquité (Pierre FRANTZ, La fraternité héroïque dans le théâtre républicain de la Révolution, pp. 203-214). Les deux dernières études sont consacrées à la question de l'idéal de la femme héroïque. Jean-Marie Roulin démontre de quelle manière, après 1790 , l'héroïsme au féminin prend de l'importance (L'héroïsation des femmes dans les poèmes épiques de la Révolution, pp. 215-233). Karen DE BRUIN analyse les ouvrages de Germaine de Staël pour montrer comment elle redéfinit cette notion qui caractérise aussi bien le grand homme que la femme supérieure, facteurs importants du progrès (The Helm and the Compas: the great man and the superior woman in Germaine de Staël's republic, pp. 235-255). 